\title{
A potential role of somatostatin and its receptor SSTR4 in the migration of hepatic oval cells
}

\author{
Youngmi Jung ${ }^{1}$, Seh-Hoon $\mathrm{Oh}^{1}$, Donghang Zheng ${ }^{1}$, Thomas D Shupe ${ }^{1}$, Rafal P Witek ${ }^{1}$ \\ and Bryon E Petersen ${ }^{1,2, *}$ \\ ${ }^{1}$ Department of Pathology, Immunology and Laboratory Medicine, College of Medicine, University of Florida, \\ Gainesville, FL, USA and ${ }^{2}$ Program for Stem Cell Biology, University of Florida Shands Cancer Center, \\ Gainesville, FL, USA
}

\begin{abstract}
Somatostatin (SST) is a regulatory peptide that activates G protein-coupled receptors comprised of five members (somatostatin receptors (SSTRs) 1-5). Despite the broad use of SST and its analogs in clinical practice, the spectrum of SST activities has been incompletely defined. Recently, it has been demonstrated that SST can be a chemoattractant for hematopoietic precursor cells. Since hepatic oval cells (HOCs) share common characteristics with hematopoietic stem cells, we hypothesized that SST could act as a chemoattractant for HOCs by stimulating SSTRs. Reverse transcriptase-polymerase chain reaction (RT-PCR) and Western blot assay revealed an increased expression of SST in the 2-acetyl-aminofluorene (2AAF)/partial hepatectomy (PHx) HOC induction model. Immunohistochemical staining showed the expression of SST in 2AAF/PHx-treated rat liver, as compared to normal liver. Proliferation and migration assays demonstrated that the increase of SST was related to migration of HOCs, but not their proliferation. RT-PCR and quantitative real-time PCR showed that SSTR4 was preferentially expressed by HOCs. Western blot assay and immunohistochemical staining confirmed the expression of SSTR4 by HOCs. In addition, pretreatment with anti-SSTR4 antibody cultures resulted in a dramatic reduction of cell migration as compared to that of control. Lastly, SST stimulated the rearrangement of actin filaments in HOCs, while HOCs treated with anti-SSTR4 antibody failed to do so. These results suggest a positive role for SST in the migration of HOCs, and that this effect is mediated through SSTR4. Laboratory Investigation (2006) 86, 477-489. doi:10.1038/labinvest.3700410; published online 13 March 2006
\end{abstract}

Keywords: somatostatin; somatostatin receptor; migration; hepatic oval cells

Hepatic oval cells (HOCs) are known to participate in liver regeneration under certain conditions, and are implicated in hepatic carcinogenesis. ${ }^{1}$ When liver damage is severe, and the ability of hepatocytes to divide and replace damaged tissue is compromised, HOCs are induced to proliferate. ${ }^{1}$ Morphologically, oval cells are small in size (approximately $10 \mu \mathrm{m}$ in diameter), with a large nuclear to cytoplasm ratio, and an oval-shaped nucleus. ${ }^{2}$ Proliferating oval cells in both the rat and murine models appear to radiate from the periportal region, forming

Correspondence: Dr BE Petersen, PhD, Department of Pathology, Immunology and Laboratory Medicine, College of Medicine, University of Florida, Room M641 MSB, PO Box 100275, 1600 SW Archer, Gainesville, FL 32610-0275, USA.

E-mail: petersen@pathology.ufl.edu

${ }^{*} \mathrm{BEP}$ is the inventor of patent(s) related to this technology and may benefit from royalties paid to the University of Florida related to its commercialisation.

Received 14 October 2005; revised 2 February 2006; accepted 10 February 2006; published online 13 March 2006 primitive ductular structures with poorly defined lumena. ${ }^{3}$ They are similar to bile ductular epithelial cells in their distinct isoenzyme profile, expressing certain keratin markers (eg CK19), and gammaglutamyl transpeptidase (GGT). HOCs also express high levels of alpha-fetoprotein (AFP) as well as hematopoietic stem cell markers (ie Thy-1, CD34, and C-Kit). ${ }^{4,5}$ In addition, several monoclonal antibodies, such as OV6, OC.2, and BD1, have been developed to aid in their identification. ${ }^{6-8}$ These markers may be used for isolating HOCs by fluorescence-activated cell sorting (FACS) or magnetic activated cell sorting (MACS). ${ }^{4,9}$ Petersen et $^{2} \mathrm{l}^{4}$ showed that, by using Thy-1 in conjunction with FACS sorting, a 95-97\% enriched population of oval cells could be obtained.

Though oval cells do not normally participate in the regenerative response to partial hepatectomy (PHx) or $\mathrm{CCl}_{4}$ injury, they can be made to do so by suppressing mature hepatocyte proliferation. Administration of $2 \mathrm{AAF}$ prior to and during hepatic 
injury induced by $\mathrm{PHx}$ or $\mathrm{CCl}_{4}$ will block the proliferation of hepatocytes by interfering with the cyclin D1 pathway. Oval cell proliferation can thus be induced in these otherwise non-oval cell-aided regenerating models. ${ }^{10,11}$ In HOC-mediated liver regeneration, HOCs arise from the portal tract periphery and migrate deep into the lobular parenchyma. This HOC distribution suggests that HOCs may be mobile. Based on ultrastructural studies in rat liver, it has been proposed that HOCs migrate by amoeboid movement with the help of pseudopodia. ${ }^{12}$ Trafficking, mobilization, and homing of stem cells are multifactorial processes that are regulated not only by adhesion molecules and cytokines, but also by chemotactic factors that direct transendothelial migration. ${ }^{13}$

Somatostatin (SST) is a unique regulatory hormone, which was first reported by Brazeau et al ${ }^{14}$ as a hypothalamic hormone inhibiting growth hormone (GH) secretion. SST has two biologically active forms, SST-14 and SST-28, which are generated as C-terminal products from pro-SST. SST-14 was originally described in the hypothalamus, and the amino-terminally extended SST-28 was discovered later in the gut. ${ }^{15}$ SST-14 and SST-28 are predominantly expressed in neurons and secretory cells in the central and peripheral nervous systems, gastrointestinal tract, pancreas, pituitary, kidney, retina, and immune system. ${ }^{16}$ The major action of this neuropeptide includes inhibition of hormone secretion from the pituitary, the pancreas, as well as other endocrine and exocrine secretion in a number of various organs. ${ }^{17}$ SST has also been shown to control the proliferation of normal and tumor cells. ${ }^{18}$ In addition, it is involved in the differentiation and migration of thymocytes. ${ }^{19}$ These broad biological functions are mediated by five receptor subtypes, all of which belong to the seven $\alpha$-helical transmembrane domain G protein-coupled receptor (GPR) family. Somatostatin receptors (SSTRs) are widely distributed throughout many tissues and show different functions in various cell and tissue types. ${ }^{18,20}$ However, studies on receptor expression in various tumors reveal inconsistencies, which are also observed in rat liver studies. ${ }^{21,22}$ Reynaert et $a l^{22}$ reported the presence of SSTRs 1-3 in activated hepatic stellate cells in $\mathrm{CCl}_{4}$-treated rats, but not in normal rat liver. However, Bruno et $a l^{21}$ provides the observation of SSTR3 mRNA in normal rat liver. Another study shows the expression of SSTRs 2, 3, and 5 by activated stellate cells in Sprague-Dawley rats. ${ }^{23}$ Therefore, inconsistent data on individual receptor subtypes have lessened the therapeutic potential of receptor subtype-specific or universal analogs in oncological and certain endocrine disorders.

Despite the broad use of SST and its analogs in clinical practice, the spectrum of SST activities has been incompletely defined. Recent evidence has emerged that neuroendocrine-like SST-producing cells are present at the interface between bone and bone marrow, a location where the most primitive hematopoietic cells reside. ${ }^{24}$ SST can act as a chemoattractant for primitive hematopoietic progenitor cells, which is mediated exclusively via SSTR2. ${ }^{25}$ Given that HOCs share common characteristics with hematopoietic stem cells, ${ }^{26}$ these novel findings led to the hypothesis that SST could possibly influence the migration of HOCs.

In the present study, the 2-acetyl-aminofluorene (2AAF) followed by a PHx model for HOC activation was utilized in order to show the effect of SST on the migration of HOCs. SST and the SSTR 1-5 expression patterns were examined via molecular and biochemical techniques. Also, the chemotactic ability of SST for HOCs was investigated. The current study demonstrates that SST induces HOC migration via SSTR4.

\section{Materials and methods}

\section{Animals}

Male F344 rats (age 6-8 weeks, weight 130-150 g) were purchased from Charles River Laboratories and maintained on standard laboratory chow and daily cycles of alternating $12 \mathrm{~h}$ of light and dark. They were used at approximately 8-10 weeks of age and $150-180 \mathrm{~g}$ weight. All animal work was conduced under protocols approved by the IACUC at the University of Florida.

\section{Rat Oval Cell Activation Protocol}

The basic design of the 2AAF/injury models has been described previously by Petersen et al. ${ }^{4}$ Briefly, $2 \mathrm{AAF}$ pellets $(70 \mathrm{mg} / 28$ day release, $2.5 \mathrm{mg} /$ day) were inserted subcutaneously 7 days prior to surgical resection of the hepatic mass (PHx injury). This follows protocols similar to those described by Novikoff et $a l^{27}$ and Hixson et al. ${ }^{7}$ Normal rat liver was used as a time zero-control. PHx $(70 \%)$ were induced as described by Higgins and Anderson. ${ }^{28}$

\section{HOC Preparation}

To isolate HOCs, the 2AAF/PHx oval cell activation model was used. ${ }^{29}$ The liver was harvested at 11 days post-PHx induction and cells were isolated via standard two-step collagenase perfusion. The obtained cells were gradient centrifuged at $50 \mathrm{rpm}$ to isolate hepatocytes. The nonparenchymal cell (NPC) fraction containing the HOCs was collected at $300 \mathrm{rpm}$. Isolated cells were incubated with antiThy-1 FITC-conjugated antibody, followed by antiFITC microbeads. After incubation, cells were positively selected using MACS sort. Cell viability was determined to be $>90 \%$, as established by trypan blue exclusion. ${ }^{30}$ After isolation, HOCs were re-suspended in Iscove's modified Dulbecco's medium (IMDM, purchased from GIBCO, Grand Island, 
NY, USA) $(10 \%$ FBS, $1 \%$ insulin, $1 \times$ antibioticantimycotic) for experiments. ${ }^{8}$

\section{Immunohistochemistry}

BrdU (Dakocytomatin, Carpinteria, CA, USA) staining was conducted as described by Sum et al. ${ }^{31}$ All immunostaining was performed on HOCs, cytocentrifuged HOCs, or frozen liver sections using standard staining protocols. Samples were fixed and permeabilized, saturated, and processed for immunostaining with primary antibodies. Anti-SST (Santa Cruz Biotech., Santa Cruz, CA, USA), CD45 (Becton Dickinson, San Jose, CA, USA), Thy-1 (Becton Dickinson), OV6 (a kind gift from Dr Stewart Sell), SSTR4 (Santa Cruz Biotech.), and F-actin (Sigma-Aldrich Corp. St Louis, MO, USA) antibodies were used in this procedure. Vector ABC kit (Vector Laboratories, Burlingame, CA, USA) and DAB reagent (Dako Comp.) were employed in the detection procedure. For double immunofluorescent staining, Texas red anti-goat IgG (Vector Laboratories) and Fluor anti-mouse IgG (Vector Laboratories) were used as secondary antibodies.

\section{RT-PCR, Real-Time PCR}

RT-PCR and real-time PCR were performed as described by Bar et al. ${ }^{32}$ Oligonucleotide primers specific for SST and SSTRs were designed with Primer 3 software (http://frodo.wi.mit.edu/cgi-bin/ primer3/primer3_www.cgi) and GenBank entries: SST (308 bp) 5'-TGG CAG AAC TGC TGT CTG AG$3^{\prime}$ forward, 5'-TAA CGC AGG GTC TAG TTG AGC-3' reverse, SSTR1 (365 bp) 5'-CAC GCA CCG CAG CCA ACA-3' forward, 5'-GGA AGC CGT AAG AGG ATG GGG TT-3 ${ }^{\prime}$ reverse, SSTR2 (376 bp) 5'-ATC ATC AAG GTG AAG TCC TCT-3' forward, 5'-GGG TCT CCG TGG TCT CAT T-3 ${ }^{\prime}$ reverse, SSTR3 (329 bp) 5'-GGG GAG TTT CAG AAA GCA AT-3' forward, 5'-TTG GGC AAG TCA CTT CTC TC-3' reverse, SSTR4 (364 bp) 5'-TCG TGG GGG TGA GGC GT AG-3' forward, 5'-CAT AGA GAA TCG GGT TGG CAC AG$3^{\prime}$ reverse, SSTR5 (388 bp) 5'-CAC GGA TGT CCA GGA GGG-3' forward, 5'-GTA GAG CAG GGG GTT GGC ACA-3' reverse. The following primers were used for real-time PCR: SSTR4 (145 bp) 5'-ATG TGT CCC TC TCC TCA GC-3' and 5'-TCT TCC TCA GCA CCT CCA GT-3'. These sequences for SSTR4 were obtained from Bar et al. ${ }^{32}$ All PCR products were directly sequenced for genetic confirmation using an AmpliTaq cycle sequencing kit (PerkinElmer, Boston, MA, USA).

\section{Proliferation Assay}

Prior to cells being placed in culture, trypan blue exclusion assay was performed. At the time of plating, cell viability was measured at $>95 \%$. Cells were seeded in a six-well plate $\left(4.5 \times 10^{4}\right.$ cells/well $)$ and grown in IMDM supplemented with 10\% FBS. After $48 \mathrm{~h}$, the medium was replaced with serumfree IMDM for $16 \mathrm{~h}$. The cells were subsequently cultured with $0.5 \%$ bovine serum albumin (BSA)containing medium, or medium with addition of $10 \%$ FBS or SST at a concentration of $100 \mathrm{nM}$. Cells were counted after 1, 2, and 3 days, and trypan blue dye exclusion was used as an indicator of cell viability. All experiments were performed three times to ensure statistical significance.

\section{Migration Assay}

Migration was assessed in Transwell culture dishes with $5 \mu \mathrm{m}$ pore filters (Transwell, $6.5 \mathrm{~mm}$ diameter, 24-well cell clusters; Coring Incorporated Costar, Coring, NY, USA) that were precoated overnight at $4{ }^{\circ} \mathrm{C}$ with $0.001 \%$ collagen. Cells $\left(7.5 \times 10^{4}\right)$ were suspended in IMDM (10\%FBS, 1\% insulin), and were allowed to attach overnight. Unadherent cells were removed from the top of the transwell chamber and attached cells were re-fed in the migration buffer (IMDM). At this time, the motility assay was initiated by transferring the entire transwell chamber to a new cluster plate well containing various doses of SST-14 (synthesized by the Interdisciplinary Center for Biotechnology Research at the University of Florida) (1, 10, 100, $1000 \mathrm{nM}$ ) in migration buffer. After determining the optimal concentration of SST through preliminary studies, migration buffer containing $100 \mathrm{nM}$ SST was placed in the lower chamber and plates were maintained at $37^{\circ} \mathrm{C}$, $5 \% \mathrm{CO}_{2}$ for either 4 or $6 \mathrm{~h}$. In some experiments, cells were pretreated for $30 \mathrm{~min}$ with anti-SSTR4 antibody (5 and $10 \mu \mathrm{g} / \mathrm{ml}$ ). As a negative control, SST was either not added to the lower chamber or added to both lower and upper chambers. At the end of the experiment, cells were fixed and stained as described by Stolz et al. ${ }^{33}$ Cells that had migrated to the bottom of the transwell filter were enumerated by counting each transwell chamber, at $\times 4$ magnification. Each migration assay was performed a minimum of three times.

\section{Western Blot Assay}

Whole liver tissue or HOCs were homogenized in Triton lysis buffer (20 mM Tris, pH 7.4, $137 \mathrm{mM}$ NaCl, $10 \%$ glycerol, $1 \%$ Triton X-100, $2 \mathrm{mM}$ EDTA, $1 \mathrm{mM}$ PMSF, $10 \mathrm{mM} \mathrm{NaF}, 5 \mu \mathrm{g} / \mathrm{ml}$ aprotinin, $20 \mu \mathrm{M}$ leupeptin, and $1 \mathrm{mM}$ sodium orthovanadate) and centrifuged at $10000 \mathrm{~g}$ for $15 \mathrm{~min}$. Protein concentrations were measured using the Lowry assay. Immunoblotting was performed using 1:500 anti-SST (sc13099, Santa Cruz Biotech.), 1:150 anti-SSTR4 (sc11620), and 1:5000 anti- $\beta$ actin (ab6276-1000, abcom. Stockholm, Sweden) antibodies. Immunocomplexes were detected with horseradish-peroxidase-conjugated secondary 
antibodies. Membranes were developed by chemoluminescence (ECL; Amersham Bioscience, Buckinghamshire, UK).

\section{Statistical Analysis}

All results are expressed as the mean \pm s.d. Statistical differences were determined by Student's $t$-test. $P$-values $<0.05$ were considered to be statistically significant.

\section{Results}

\section{Increased Expression of SST in the HOC Induction Model}

To examine whether SST is involved in liver regeneration by HOCs, the $2 \mathrm{AAF} / \mathrm{PHx}$ model was employed. In this model, HOC proliferation peaks on approximately day 9 and continues through day 13. ${ }^{1}$ Small cells with a large nuclear to cytoplasm ratio are observed in $2 \mathrm{AAF} / \mathrm{PHx}$-treated rat liver, radiating from the periportal region (Figure 1a). OV6, a known HOC marker, confirmed these cells as HOCs (Figure 1b). In normal rat liver, OV6 was detected in ductal cells (Figure 1d). Figure 1c shows a negative control in which anti-mouse IgG was used in place of the primary antibody. These data confirm that the $2 \mathrm{AAF} / \mathrm{PHx}$ protocol for rat HOCs is reliable and reproducible. Utilizing RT-PCR analysis with specific primers for rat SST detects newly synthesized message from the SST gene (Figure 2a). Western blot assay for SST showed that SST was initially expressed at negligible levels and increased when HOC proliferation increased, peaking at approximately day 11 of HOC activation (Figure 2b). Immunofluorescent staining revealed
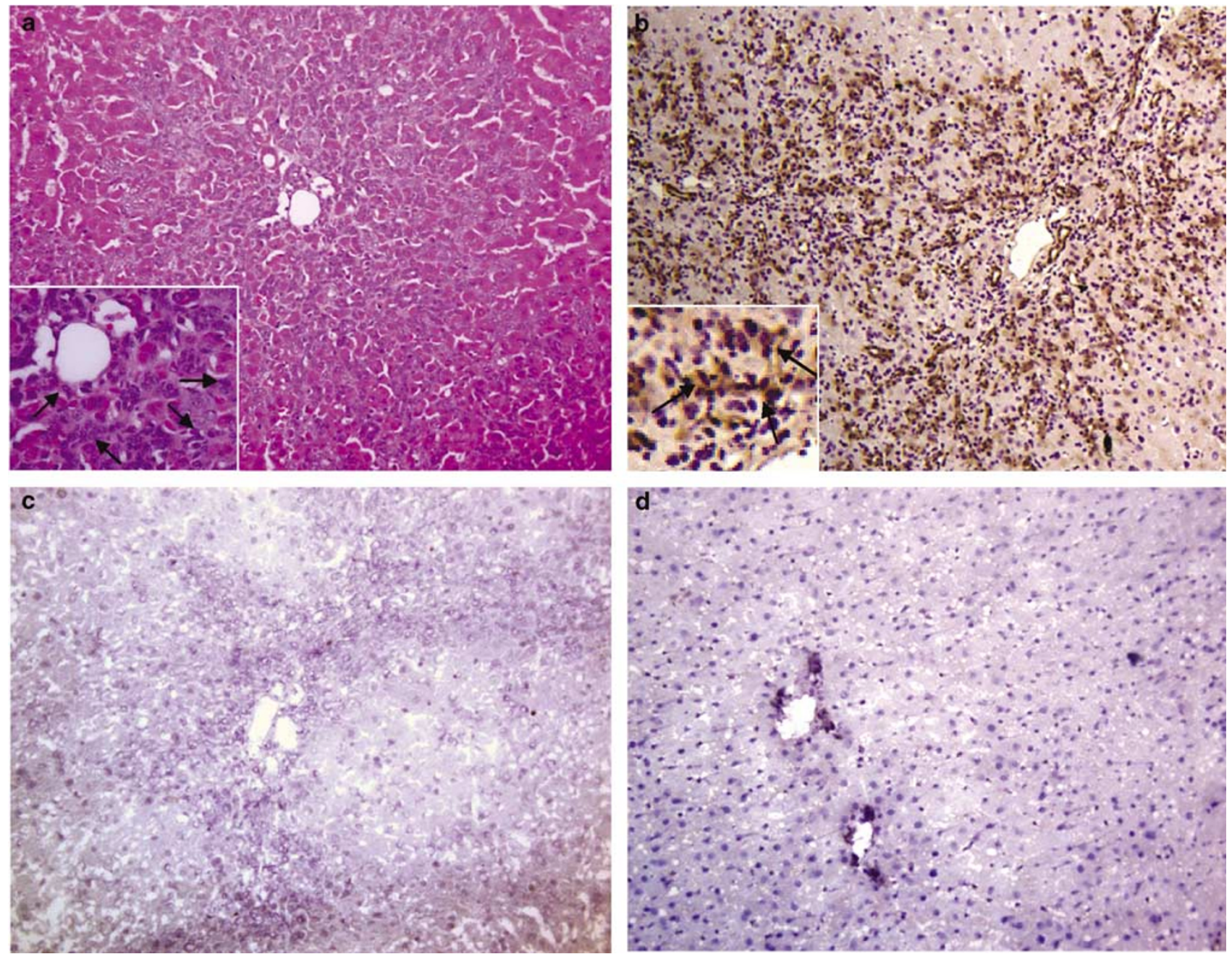

Figure $1 \mathrm{HOC}$ induction in the 2AAF/PHx model. (a) Hematoxylin-eosin staining at day 11 liver section of $2 \mathrm{AAF} / \mathrm{PHx}$-treated rats $(\times 20$, inserted image $\times 40$, arrows indicate small HOCs). (b) Immunohistochemical staining for OV6 at day 11 liver section of $2 \mathrm{AAF} / \mathrm{PHx}-$ treated rats. Brown color indicates OV6-positive cells $(\times 20)$. (c) Liver section from the same animal as in (a) and (b), stained by antimouse immunoglobulin $G$ serving as a negative control $(\times 20)$. (d) Liver section from normal liver tissue $(\times 20)$. Data shown represent one of three experiments with similar results. 


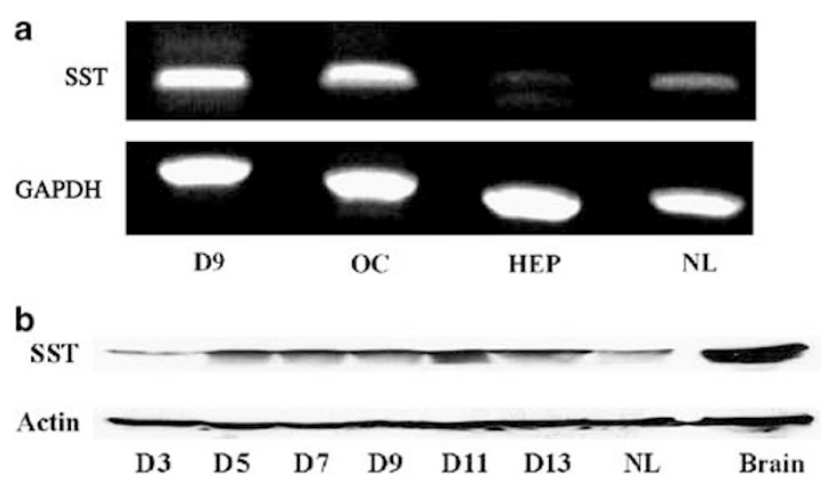

Figure 2 Increased SST expression in the HOC induction model. (a) RT-PCR of SST in 2AAF/PHx (D9), Thy-1 sorted HOCs (OC), normal hepatocytes (HEP), and normal liver (NL). GAPDH was used as an internal control. Data shown represent one of three experiments with similar results. (b) Western blot analysis for SST in liver tissue obtained from 2AAF/PHx-treated rats. Protein extracted from the brain was employed as positive control and actin as an internal control. Data shown represent one of three experiments with similar results.

few SST-positive cells within normal or PHx-treated liver (Figure 3a-c). However, the number of positive cells significantly increased within the $2 \mathrm{AAF} / \mathrm{PHx}$ model. SST was expressed on $\mathrm{CD} 45^{+}$cells early in the HOC activation process (day 5) (Figure $3 \mathrm{~d}-\mathrm{f}$ and j), whereas by day 13 of HOC activation SST expression was localized to the OV6-positive cells (Figure $3 \mathrm{~g}-\mathrm{i}$ and $\mathrm{k}$ ). These observations were visible only in the HOC activation model. This specific and increased expression of SST in HOC-mediated liver regeneration suggested a potential role of SST in HOC activation.

\section{Chemotactic Role of SST for HOCs}

SST is a pleiotropic peptide mediating inhibitory functions in various secretory and proliferative processes, as well as a stimulatory role in cell proliferation. ${ }^{18,34,35}$ These broad effects are cell typespecific. Thus, the effect of SST on HOC proliferation was investigated. Figure 4a shows that there is a significant increase in the number of HOCs after stimulation with $10 \% \mathrm{FBS}$, reaching up to $7.4 \times 10^{4}$ cells at day 3. However, SST-stimulated HOCs show only slight proliferation $\left(4.5 \times 10^{4}\right.$ cells at day 3$)$, which is similar to the level of proliferation seen in the control $\left(3.8 \times 10^{4}\right.$ at day 3$)$. In this assay, $0.5 \%$ BSA was employed in order to inhibit cell death. Therefore, HOCs in SST-containing or control medium had a normal morphology and exclude trypan blue up to the end of the experiment. To confirm this result, BrdU incorporation assay was utilized. The number of BrdU-positive cells was considerably different among the FBS, SST, and media alone (control) cultures. In all, $44 \%$ of the cells cultured in 10\% FBS were positive for BrdU, while only $14 \%$ of cells cultured in SST-containing medium were BrdU-positive (Figure $4 \mathrm{~b}$ ). There was no significant difference in the number of BrdUpositive cells between the SST-including medium (SST) and untreated medium (control). These results demonstrated that SST did not affect the proliferation of HOCs.

Recently, SST has been shown to function as a chemoattractant for immature neuronal and hematopoietic cells. ${ }^{25,36}$ Hence, this study was designed to determine whether SST might be involved in migration of HOCs. In the migration assay, when SST was added to the medium in the lower chamber, HOCs crossed the filter in a dose-dependent fashion. In the presence of $100 \mathrm{nM}$ SST, the number of migrating HOCs showed a significant peak, a threefold increase on average (Figure 4c). However, HOCs showed limited mobility in the absence of SST or in the presence of SST in both the lower and upper chambers. Migration assay using the transwell chamber clearly demonstrated that HOCs migrated along the SST gradient, suggesting that increased expression of SST might be involved in HOC migration.

\section{Expression of SSTR4 in HOCs}

All of the known functions of SST are mediated by five receptor subtypes. Therefore, it was hypothesized that the effect of SST in HOC migration might be mediated by a certain type of receptor. In order to determine receptor subtype expression profiles by HOCs, RT-PCR was performed for each SSTR subtype. SSTRs 1, 2, 4, and 5 were upregulated in HOCs, compared to the expression of these receptors in hepatocytes and normal liver. However, it was found that SSTR4 was the only subtype expressed exclusively by HOCs (Figure 5a, asterisks). All other receptor subtypes were found in normal liver and hepatocytes, as well as HOCs. Thus, SSTR4 was thought to have a specific function in HOCs. Realtime PCR was conducted to obtain quantitative data for SSTR4 expression in the HOC induction model. Gene expression for SSTR4 determined by real-time PCR confirmed that expression of SSTR4 significantly increased during HOC activation, peaking at around day 7 post-PHx, whereas normal liver was devoid of any such expression (Figure 5b). In addition, immunohistochemical staining showed the SSTR4 protein within the HOC population area (Figure 5c). Also, Western blot assay of protein extract from Thy-1 sorted HOCs showed a band corresponding to glycosylated SSTR4 $(70 \mathrm{kDa})$, while this band was not detected in normal liver (Figure 6a). Double immunofluorescent staining on purified and cytocentrifuged HOCs showed that a portion of the Thy-1-positive and OV6-positive populations express SSTR4 protein (Figure 6b). Considering the rare detection of SSTR4 in the normal liver, the significant expression of SSTR4 in HOCs suggests a specific function for SSTR4 in these cells. 

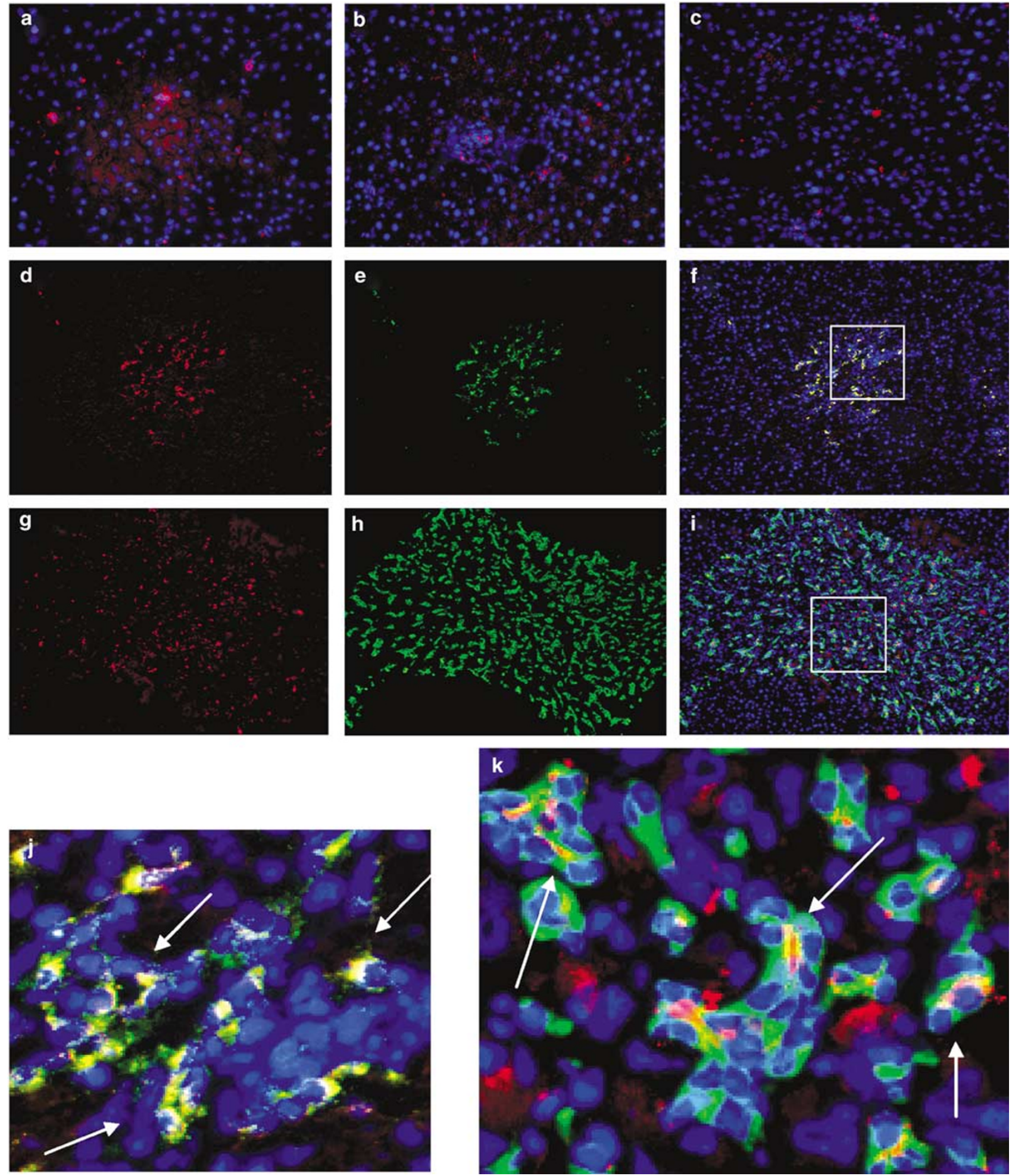

Figure 3 Immunohistochemical analysis for SST in the HOC induction model. (a) Normal liver, (b) PHx-treated liver (12 h post-PHx), and (c) PHx-treated liver (24 h post-PHx) were stained with SST (Texas red). Representative slides were viewed at $\times 20$ magnification. DAPI (blue) was employed for nuclear staining. Double immunofluorescent staining for SST (d; Texas red), CD45 (e; FITC), and merged image (f) of (d) and (e) in 2AAF/PHx-treated rats (day 5, × 10). (g-i) Double immunofluorescent staining for SST (g; Texas red), OV6 (h; FITC), and merged image (i) of (g) and (h) in 2AAF/PHx-treated rats (day 13, $\times 10$ ). (j) Magnified image from squares in (f). (k) Magnified image from squares in (i) (colocalized cells appear as yellow to orange). Arrows indicate colocalization with SST and CD45 (j) or OV-6 $(\mathbf{k})$. Original magnifications of $(\mathbf{j})$ and $(\mathbf{k})$ are $\times 10$ and $\times 20$, respectively. Data shown represent one of three experiments with similar results. 

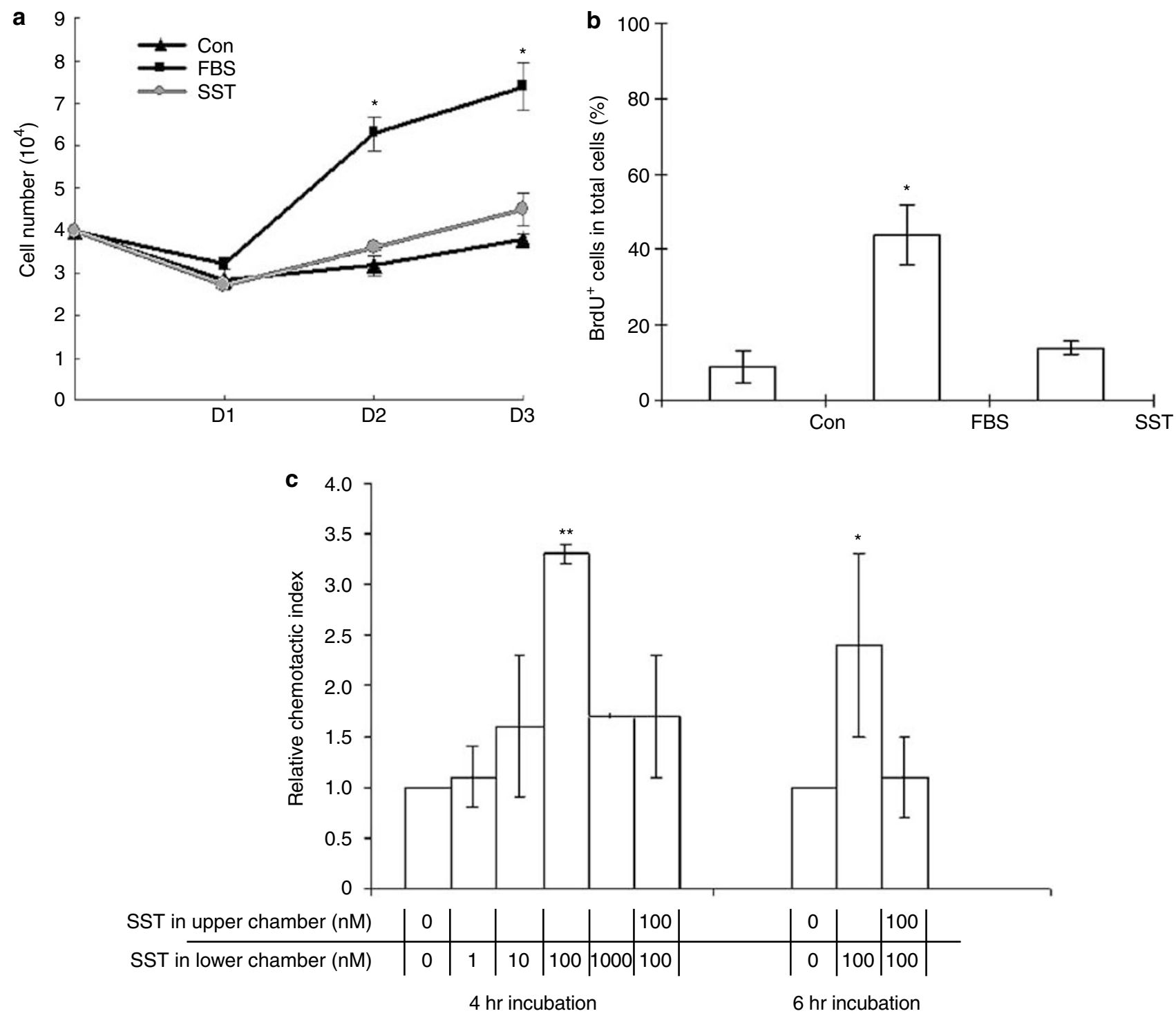

Figure 4 Potential role of SST as chemoattractant for HOCs. (a) Effects of SST on HOC proliferation. HOCs were incubated in 10\% FBS supplemented IMDM medium ( $\mathbf{\square}$, FBS), or serum-free IMDM medium containing $0.5 \%$ BSA with SST at $100 \mathrm{nM}(\bullet$, SST), or without SST ( $\boldsymbol{\Lambda}$, control) for the indicated times. These media were changed every day. Each point represents the mean \pm s.d., $n=3$, of independent experiments $\left({ }^{*} P<0.001\right)$. (b) BrdU incorporation assay. Cells were seeded in a six-well plate $\left(4.5 \times 10^{4}\right.$ cells $/$ well) and grown in IMDM supplemented with $10 \%$ FBS. After $48 \mathrm{~h}$, the medium was replaced with serum-free IMDM for $16 \mathrm{~h}$. The cells were subsequently cultured with $0.5 \%$ BSA-containing medium, or medium with addition of $10 \%$ FBS or SST at a concentration of $100 \mathrm{nM}$. After $1 \mathrm{~h}$ incubation, $100 \mu \mathrm{M}$ of BrdU was added. Cells were fixed after $24 \mathrm{~h}$. BrdU-positive cells are presented as percentage of total cell number. Data shown represent one of three experiments with similar results $\left({ }^{*} P<0.01\right)$. (c) Migration assay using Transwell chamber. HOCs were seeded on the top of the chamber with $1,10,100$, or $1000 \mathrm{nM}$ of SST protein placed in the bottom chamber or $100 \mathrm{nM}$ of SST protein placed in both upper and lower chamberd. Controls were used with no SST protein in either chamber. Data represent the mean value \pm s.d. of three independent experiments. Data were normalized for each independent experiment with respect to control migration $\left({ }^{*} P<0.05,{ }^{*} P<0.01\right.$, relative chemotactic index vs control).

\section{SST Directing HOC Migration through SSTR4}

SST and SSTR4 are expressed in the HOC induction model, and SST acts as a chemoattractant for HOCs in migration assays. These results suggest that SST might exert a chemotactic effect on HOCs via SSTR4. To test this possibility, migration assays using transwell chambers were performed on HOCs pretreated with anti-SSTR4 antibody. This antibody was raised against the N-terminus of mouse SSTR4 and made to cross-react with SSTR4 of rat. As shown in Figure $7 \mathrm{a}$, the mobility of HOCs was abolished by adding 5 or $10 \mu \mathrm{g} / \mathrm{ml}$ anti-SSTR4 antibody before SST stimulation, as compared to the uninhibited migration of HOCs toward SST. Hence, the migratory effect of SST on HOCs appears to be related to SSTR4.

Dynamic changes in actin filaments are related to various cellular processes, such as cell motility, cell cycle control, cellular structure, and cell signaling. ${ }^{37}$ 
a

SSTR1

SSTR2

SSTR3

SSTR4
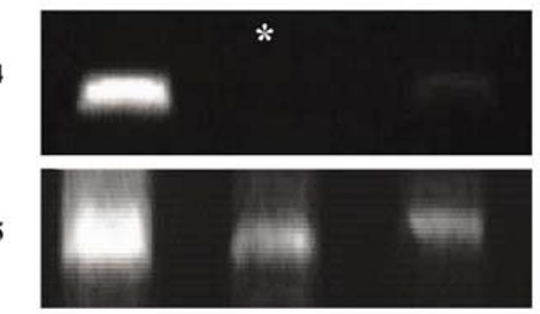

GAPDH

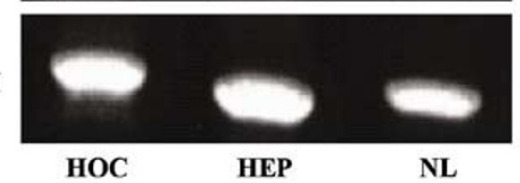

SSTR5

b

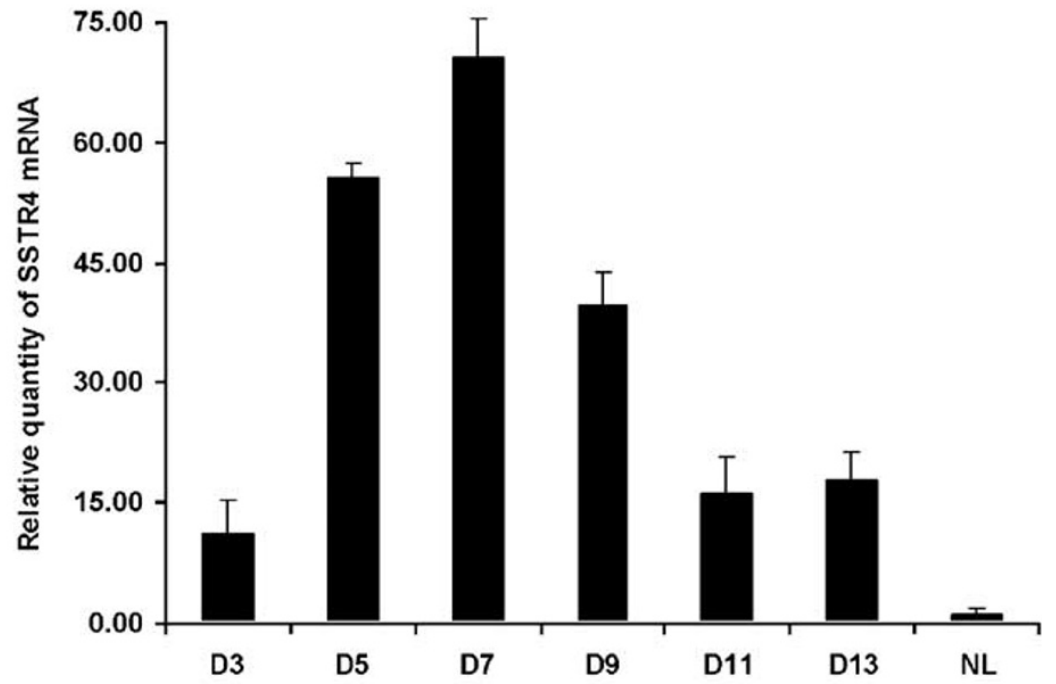

C

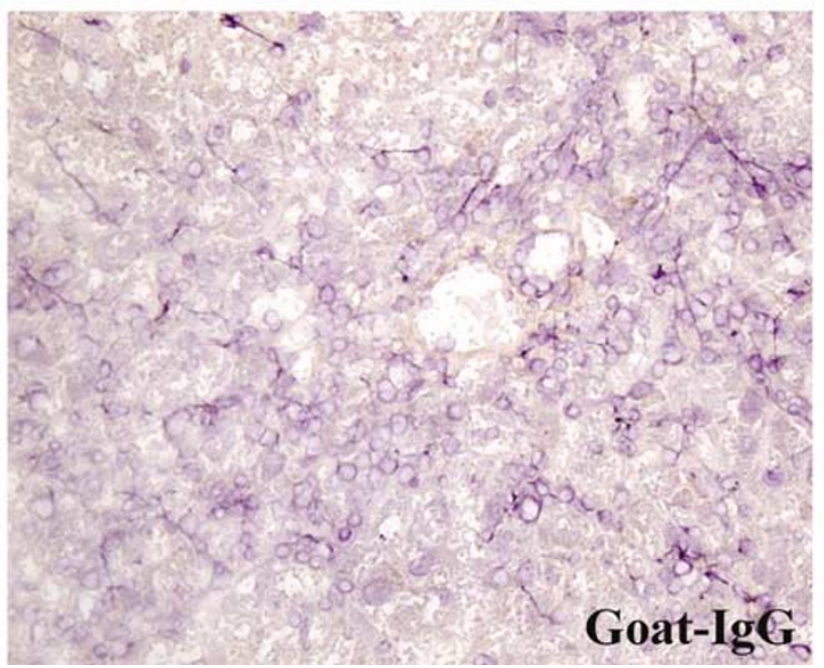

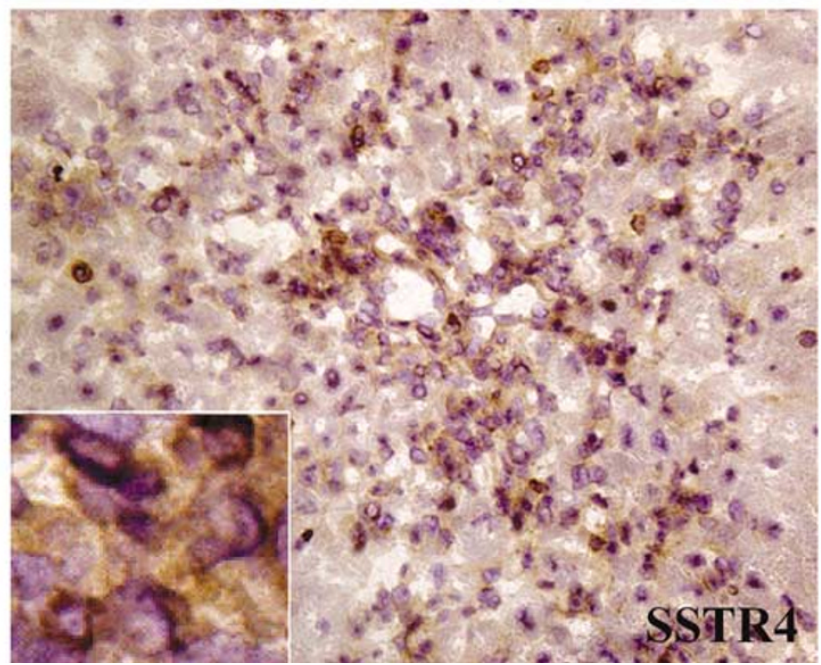

Figure 5 Detection of SSTR4 in HOC-aided liver regeneration. (a) RT-PCR analysis of SSTR subtypes in HOCs, normal hepatocytes (HEP), and normal liver (NL). Asterisks indicate no band for SSTR4 in HEP sample. GAPDH was used as internal control. Data shown represent one of three experiments with similar results. (b) Relative quantification of SSTR4 in HOC induction model using real-time PCR. Data represent the mean value \pm s.d. (c) Immunohistochemical staining for SSTR4 at day 9 liver section of HOC induction model (original magnification was taken by using a $\times 40$ objective). Anti-goat immunoglobulin (IgG) was employed in staining liver section from the 2AAF/PHx-treated rats, in order to serve as negative control. Data shown represent one of three experiments with similar results.

The rearranged actin filaments form discrete structures, such as stress fibers, lamellipodia, filopodia, and membrane ruffles, at the edges of cell membrane. These structures are essential for cell migration. ${ }^{37}$ Therefore, additional studies were incorporated to determine whether SST/SSTR4 would induce rearrangement of actin filaments in HOCs. HOCs cultured in IMDM without SST showed evenly distributed actin filaments throughout the cell (Figure 7b, upper image). In contrast, treatment with $100 \mathrm{nM}$ SST induced the distribution of actin filaments into the cell membrane to form cell mobility structures at the leading edges of the cells (Figure 7b, middle image). These mobility structures were not detected in HOC treated with SST along with the anti-SSTR4 antibody (Figure 7b, lower image). These data show that the rearrangement of actin filaments in HOCs occurs following stimulation of SSTR4 by SST. 
a

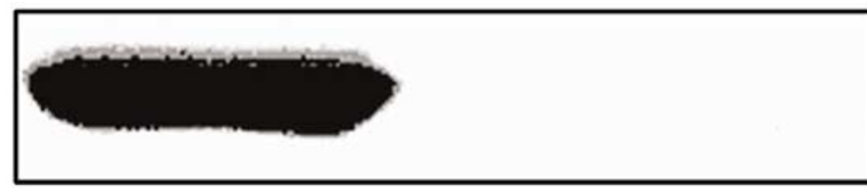

\section{SSTR4}

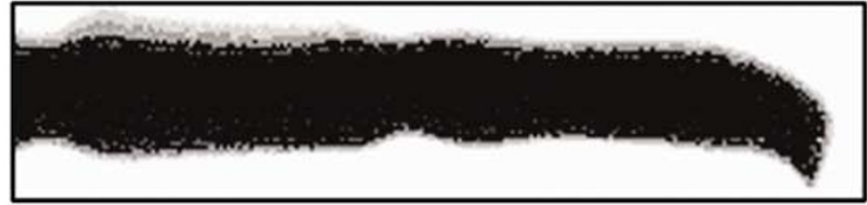

actin

HOC

b
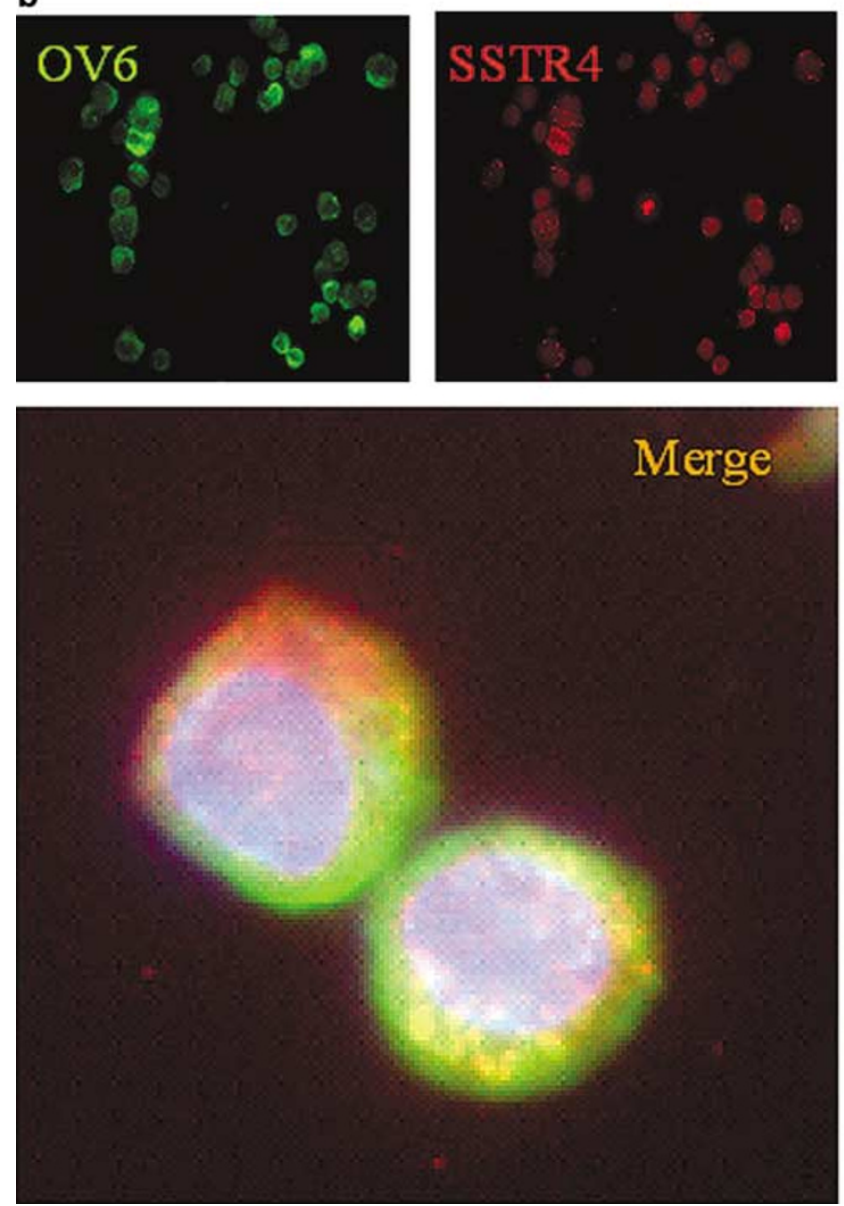

NL
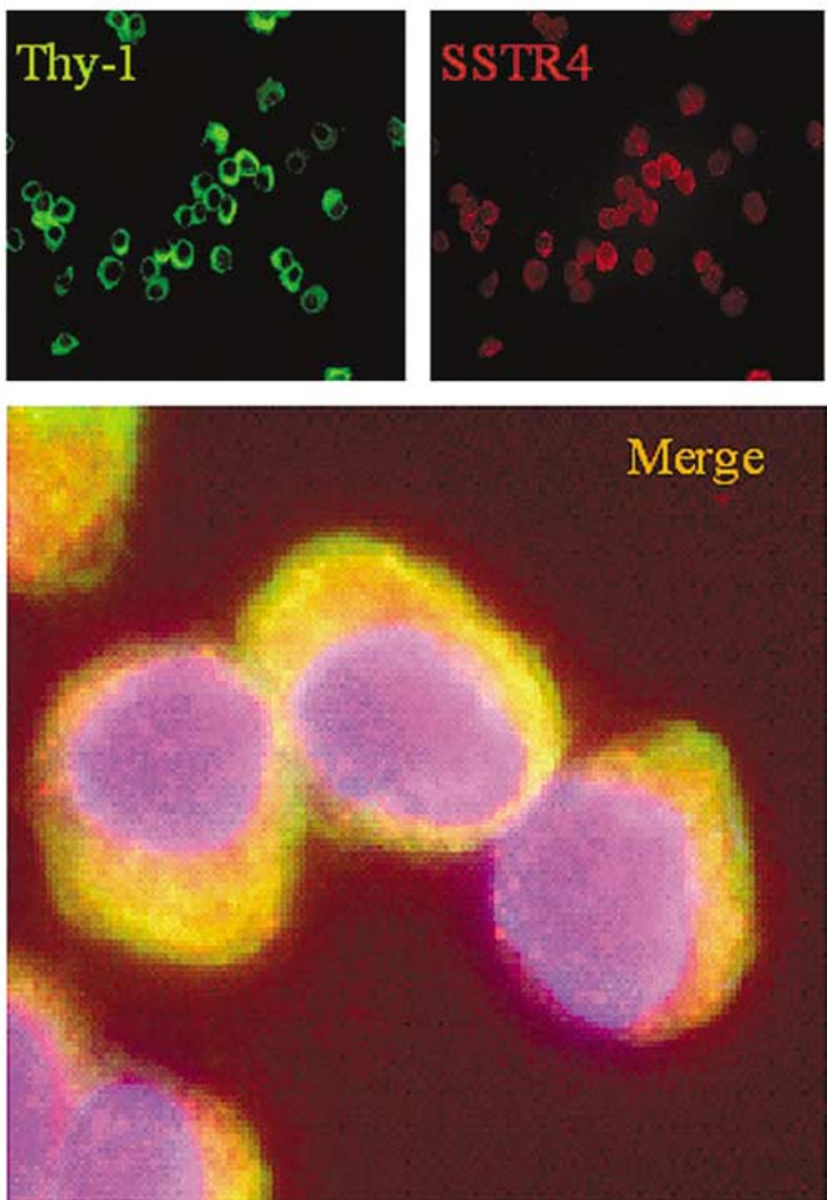

Figure 6 Expression of SSTR4 by HOCs. (a) Western blot analysis for SSTR4 in Thy-1 sorted cells from 2AAF/PHx-treated rats and total liver tissue from normal rats. Data shown represent one of three experiments with similar results. (b) Double immunofluorescent staining for SSTR4 (Texas red) and Thy-1 or OV6 (FITC) on cytocentrifuged preparations of Thy-1 sorted cells from 2AAF/PHx-treated rats (magnification of the small images is $\times 40$; original magnification of the merge images is $\times 40$ ). In merged image, SSTR4 are shown as yellow to orange. Data shown represent one of three experiments with similar results.

\section{Discussion}

SST is a regulatory peptide with a wide variety of functions, mainly linked to the neuroendocrine and immune systems. ${ }^{38}$ Thus far, SST has been found to act predominantly as an inhibitor of secretory and proliferative responses. However, recent studies have shown that SST can act as a chemoattractant for primitive hematopoietic progenitor cells. ${ }^{25}$ There is increasing evidence revealing common characteristics between HOCs and hematopoietic stem cells. ${ }^{4,39,40}$ The novel function of SST in acting as a chemoattractant for stem cells led us to propose that SST could affect HOC migration. The focus of these studies was to determine whether or not there was ligand/receptor interaction during oval-cell-aided regeneration. In order to achieve our goal, we chose to use the time of maximum SST protein expression, 
which was determined to day 11 post-PHx, which is clearly shown via Western analysis (Figure 2b). To confirm the expression if SSTR4 was also present at

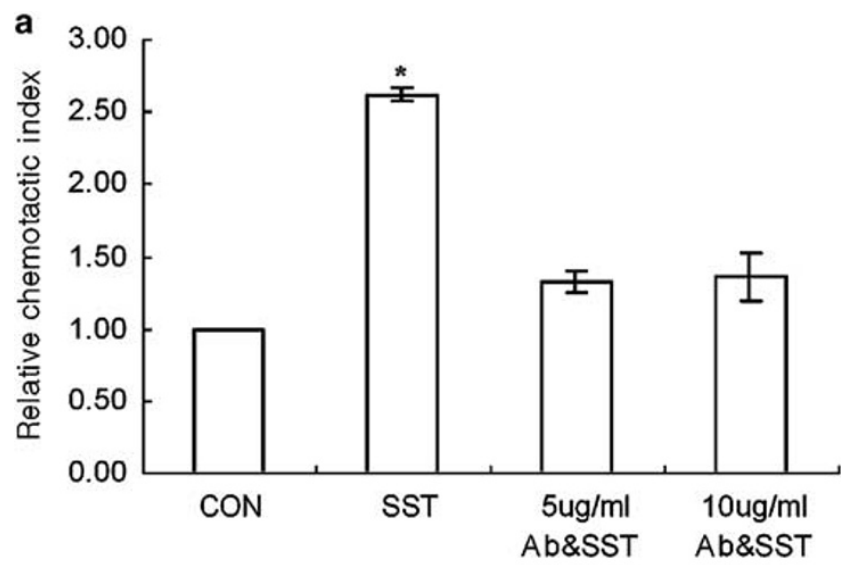

b
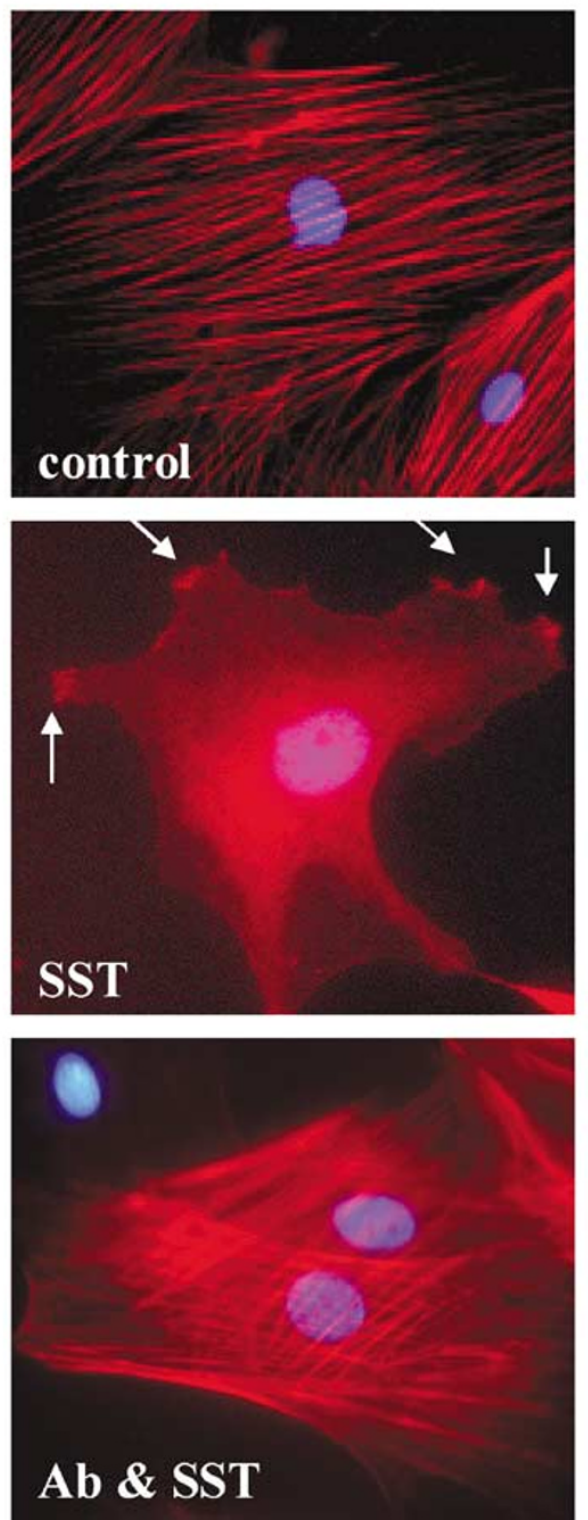

day 11, immunohistochemistry (Figure 5c) and Western analysis (Figure 6a) were performed. This also indicates that the ligand is present within the liver at the same time that the receptor is present on the HOCs. We also show that SST stimulates cell migration and cytoskeletal rearrangement, and the effects of SST appear to be mediated by the receptor SSTR4 subtype.

Previous studies have shown a correlation between HOC proliferation and inflammation within the liver parenchyma. ${ }^{12}$ The present study shows that expression of SST by CD45-positive immune cells occurs early in HOC activation and is followed by expression in OV6-positive oval cells. In normal or PHx-(alone)-treated liver, very little SST expression was observed (Figure $3 a-c)$. The finding that the inflammatory cells affect the activation and localization of stem cells strongly suggests that one or more cytokines produced during inflammation function as growth or chemotactic factors for the HOCs. ${ }^{12}$ Accordingly, this may suggest that $\mathrm{CD} 45^{+}$cells express SST in response to tissue damage, leading to recruitment of HOCs to the site of injury. These newly recruited HOCs appear to also express SST, amplify the activation signal, bringing additional HOCs to mediate liver regeneration.

In the migration assay, four different concentrations $(1,10,100$, and $1000 \mathrm{nM})$ of SST were tested. A bell-shaped dose response was observed (Figure 4c). This pattern is often observed in G-coupled receptor-mediated responses and is thought to occur via desensitization. ${ }^{25}$ Based on these results, a concentration of $100 \mathrm{nM}$ of SST was chosen as the optimal concentration for these studies. In 4-h migration assay, HOCs migrated with a significant chemotactic response. However, this response of HOCs slightly decreased following 6-h incubation. There could be several factors to explain this. First, SST is an unstable peptide, which could degrade and lose its effectiveness. Second, because of its small size, SST could diffuse between the two chambers, allowing the cells access without migration.

Figure 7 Effects of SST and SSTR4 on HOC migration and actin rearangement. (a) Stimulation of HOC migration by SST and SSTR4. HOCs were subjected to chemotaxis assays with $100 \mathrm{nM}$ SST (SST) or without SST (Con). Cells were treated with antiSSTR4 antibody (5 and $10 \mu \mathrm{g} / \mathrm{ml}$ ) and cultured in $100 \mathrm{nM}$ SSTcontaining medium for $4 \mathrm{~h}$ ( $5 \mathrm{Ab}$ and SST and $10 \mathrm{Ab}$ and SST). Addition of anti-SSTR4 antibody significantly reduced the chemotactic response. Data were normalized for each independent experiment with respect to control migration $\left({ }^{*} P<0.01\right.$, relative chemotactic index vs control). Data represent mean value \pm s.d. of three independent experiments. (b) Rearrangement of actin filament in HOCs through SST and SSTR4. HOCs were incubated in IMDM medium containing no addition (control) and $100 \mathrm{nM}$ SST-containing medium for $4 \mathrm{~h}$ (SST). Cells were pretreated with anti-SSTR4 antibody and then incubated in $100 \mathrm{nM}$ SST-containing medium for $4 \mathrm{~h}$ (anti-SSTR4 $\mathrm{Ab}$ and SST) (all images $\times 40$ ). Data shown represent one of three experiments with similar results. 
The chemotactic response of HOCs to the SST gradient led us to predict that HOCs might express one or more of the particular receptor subtypes responsible for the chemotactic properties of SST. The biological effects of SST are mediated by SSTRs that are highly cell-specific. Physiological responses vary with the expression of individual receptor subtypes that are functionally coupled to the effectors of signal transduction, resulting in physiological impact. ${ }^{20}$ Within the context of this study, SSTR4 was uniquely expressed by HOCs within the liver. The expression of SSTR4 in rat liver has not been observed previously. Consequently, detection of SSTR4 in the HOC population during liver regeneration supports the hypothesis that SSTR4 is involved in the action of SST as a chemoattractant. This notion is further supported by the fact that SST fails to stimulate HOC migration when SSTR4 is blocked (Figure 7a). Another possible explanation for the lack of migration within the transwell studies could be from an apoptotic effect brought on by antibody exposure. It has been reported that SST can act as an antiproliferative agent; however, these studies were conducted on cancer cell lines (MCF-7 and CHO-K1) and it has been shown that these cells can be coxed into apoptosis via the SHP-1/caspase 8 pathway. ${ }^{41}$ Sharma et $a l^{42}$ showed that of all the different receptor subtypes, the only one capable of inducing apoptosis was SSTR3. In addition, two independent studies, Anderson et $a l^{43}$ and Sellers et $a l,{ }^{44}$ showed that only SSTR4 was capable of inducing a proliferative effect in cells via the phosphorylation of STAT3. To date there are no data showing an apoptotic effect through SSTR4. It should also be pointed out that in Figure $7 \mathrm{~b}$ we show oval cells untreated (upper panel), treated with SST (middle panel) and SST/antibody (lower panel), and stained for actin. In untreated cells the actin stress fibers are visible uniformly distributed throughout the cell. When SST is given to the cell culture, these actin fibers are lost and focal adhesion points are seen along the edge of the cell membrane. However, when the cells are exposed to SST plus antibody, the actin fibers are intact and the cells appear to be normal. It is also worth pointing out that no irregular/pyknotic nuclei were seen following SSTR4 antibody treatment. This further indicates that the antibody treatment did not induce apoptosis in the migration assay.

The activation of ligand induces SSTR dimerization, which alters the functional properties of the receptors, such as ligand-binding affinity, agonistinduced receptor internalization, and upregulation. ${ }^{45}$ Increased expression of SSTRs 1,2 , and 5 were observed in this study (Figure 5a). Hence, it is possible that the dimerization of SSTR4 with another SSTR isotype may affect migration or other responses of HOCs. Although a role of SSTR4 in HOC migration was demonstrated in this study, further studies on the interaction among SSTRs and/ or the effect of other receptor subtypes in HOC are required. As SSTR5 was so strongly upregulated in oval cell activation, it would seem logical to focus the next set of experiments on this receptor subtype to determine if there is a role for this receptor subtype in oval cell activation and or migration.

This study demonstrates that SST induces the reorganization of actin filaments. In order for cells to migrate, F-actin requires rearrangement. Consequently, the cells can form mobility structures and move along their pathway to engraftment. With the rearrangement seen within this study, it would appear that SST is required for this rearrangement. It was also demonstrated that the effect of SST in actin rearrangement was abolished by anti-SSTR4 antibody. These data indicate that SST/SSTR4 might stimulate an upstream signal to rearrange actin filaments needed for motility. The SSTRs are coupled to Gi-protein, which has been reported to be required for homing of hematopoietic stem cells. ${ }^{46}$ This receptor class can be coupled to the activation of PI3 kinase, the downstream effectors of which, Cdc42 and Rac1, have been implicated in the formation of mobility structures. ${ }^{47,48}$ Therefore, it is conceivable that SST would mediate the migration of HOCs through the SSTR4-coupled Gi-protein/ PI3K/Rac signaling pathway, but this remains to be tested.

Stem cells 'home' or migrate to appropriate sites, where they exert unique functions such as selfrenewal and multi-lineage differentiation. The molecular mechanisms regulating stem cell homing require more study, especially given the importance of such homing in a variety of medical applications. A new function for SST and SSTR4 in HOC migration is presented in the current study. This may lead to a better understanding of HOC movement within the injured liver. However, more work is required to fully understand the significance of the present findings.

\section{Acknowledgement}

The National Institute of Health Grants DK058614 and DK065096 awarded to BEP funded this research.

\section{References}

1 Oh SH, Hatch HM, Petersen BE. Hepatic oval 'stem' cell in liver regeneration. Semin Cell Dev Biol 2002;13:405-409.

2 Fausto N. Liver stem cell. In: Arias ISD, Schachter D, kavoby W, Boyer J (eds). The Liver: Biology and Pathobiology. Raven: New York, 1994, p 1501.

3 Preisegger KH, Factor VM, Fuchsbichler A, et al. Atypical ductular proliferation and its inhibition by transforming growth factor beta1 in the 3,5-diethoxycarbonyl-1,4-dihydrocollidine mouse model for chronic alcoholic liver disease. Lab Invest 1999;79: 103-109. 
4 Petersen BE, Goff JP, Greenberger JS, et al. Hepatic oval cells express the hematopoietic stem cell marker Thy-1 in the rat. Hepatology 1998;27:433-445.

5 Omori N, Omori M, Evarts RP, et al. Partial cloning of rat CD34 cDNA and expression during stem celldependent liver regeneration in the adult rat. Hepatology 1997;26:720-727.

6 Faris RA, Monfils BA, Dunsford HA, et al. Antigenic relationship between oval cells and a subpopulation of hepatic foci, nodules, and carcinomas induced by the 'resistant hepatocyte' model system. Cancer Res 1991;51:1308-1317.

7 Hixson DC, Faris RA, Thompson NL. An antigenic portrait of the liver during carcinogenesis. Pathobiology 1990;58:65-77.

8 Yang L, Faris RA, Hixson DC. Phenotypic heterogeneity within clonogenic ductal cell populations isolated from normal adult rat liver. Proc Soc Exp Biol Med 1993;204:280-288.

9 Alison MR, Vig P, Russo F, et al. Hepatic stem cells: from inside and outside the liver? Cell Prolif 2004;37:1-21.

10 Evarts RP, Nakatsukasa H, Marsden ER, et al. Cellular and molecular changes in the early stages of chemical hepatocarcinogenesis in the rat. Cancer Res 1990;50: 3439-3444.

11 Fausto NLJ, Shiojiri N. Oval cells in liver carcinogenesis; cell lineages in hepatic development and identification of stem cells in normal liver. In: Raton SAB (ed). The Role of Cell Types in Hepatocarcinogenesis. CRC Press: Boca Raton, FL, 1992, p 89.

12 Libbrecht L, Desmet V, Van Damme B, et al. Deep intralobular extension of human hepatic 'progenitor cells' correlates with parenchymal inflammation in chronic viral hepatitis: can 'progenitor cells' migrate? J Pathol 2000;192:373-378.

13 Mohle R, Bautz F, Denzlinger C, et al. Transendothelial migration of hematopoietic progenitor cells. Role of chemotactic factors. Ann NY Acad Sci 2001;938:26-34; discussion 34-35.

14 Brazeau P, Vale W, Burgus R, et al. Hypothalamic polypeptide that inhibits the secretion of immunoreactive pituitary growth hormone. Science 1973;179: 77-79.

15 Olias G, Viollet C, Kusserow H, et al. Regulation and function of somatostatin receptors. J Neurochem 2004; 89:1057-1091.

16 Elliott DE, Blum AM, Li J, et al. Preprosomatostatin messenger RNA is expressed by inflammatory cells and induced by inflammatory mediators and cytokines. J Immunol 1998;160:3997-4003.

17 Bertherat J, Bluet-Pajot MT, Epelbaum J. Neuroendocrine regulation of growth hormone. Eur J Endocrinol 1995;132:12-24.

18 Weckbecker G, Lewis I, Albert R, et al. Opportunities in somatostatin research: biological, chemical and therapeutic aspects. Nat Rev Drug Discov 2003;2:9991017.

19 Solomou K, Ritter MA, Palmer DB. Somatostatin is expressed in the murine thymus and enhances thymocyte development. Eur J Immunol 2002;32: 1550-1559.

20 Lahlou H, Guillermet J, Hortala M, et al. Molecular signaling of somatostatin receptors. Ann NY Acad Sci 2004;1014:121-131.

21 Bruno JF, Xu Y, Song J, et al. Tissue distribution of somatostatin receptor subtype messenger ribo- nucleic acid in the rat. Endocrinology 1993;133:25612567.

22 Reynaert H, Vaeyens F, Qin H, et al. Somatostatin suppresses endothelin-1-induced rat hepatic stellate cell contraction via somatostatin receptor subtype 1. Gastroenterology 2001;121:915-930.

23 Song SH, Leng XS, Li T, et al. Expression of subtypes of somatostatin receptors in hepatic stellate cells. World J Gastroenterol 2004;10:1663-1665.

24 Godlewski A. Calcitonin and somatostatin immunoreactive cells are present in human bone marrow and bone marrow cells are responsive to calcitonin and somatostatin. Exp Clin Endocrinol 1990;96:219-233.

25 Oomen SP, van Hennik PB, Antonissen C, et al. Somatostatin is a selective chemoattractant for primitive (CD34(+)) hematopoietic progenitor cells. Exp Hematol 2002;30:116-125.

26 Lowes KN, Croager EJ, Olynyk JK, et al. Oval cellmediated liver regeneration: role of cytokines and growth factors. J Gastroenterol Hepatol 2003;18:4-12.

27 Novikoff PM, Yam A, Oikawa I. Blast-like cell compartment in carcinogen-induced proliferating bile ductules. Am J Pathol 1996;148:1473-1492.

28 Higgins GM, Anderson RM. Experimental pathology of the liver. Restoration of the liver of the white rat following partial surgical removal. Arch Pathol 1931; 12:186-202.

29 Seglen PO. Preparation of isolated rat liver cells. Methods Cell Biol 1976;13:29-83.

30 Deng J, Steindler DA, Laywell ED, et al. Neural transdifferentiation potential of hepatic oval cells in the neonatal mouse brain. Exp Neurol 2003;182:373-382.

31 Sum EY, Shackleton M, Hahm K, et al. Loss of the LIM domain protein Lmo4 in the mammary gland during pregnancy impedes lobuloalveolar development. Oncogene 2005;24:4820-4828.

32 Bar KJ, Schurigt U, Scholze A, et al. The expression and localization of somatostatin receptors in dorsal root ganglion neurons of normal and monoarthritic rats. Neuroscience 2004;127:197-206.

33 Stolz DB, Michalopoulos GK. Synergistic enhancement of EGF, but not HGF, stimulated hepatocyte motility by TGF-beta 1 in vitro. J Cell Physiol 1997; 170:57-68.

34 Rosskopf D, Schurks M, Manthey I, et al. Signal transduction of somatostatin in human B lymphoblasts. Am J Physiol Cell Physiol 2003;284:C179-C190.

35 Smalley KS, Feniuk W, Sellers LA, et al. The pivotal role of phosphoinositide-3 kinase in the human somatostatin sst(4) receptor-mediated stimulation of p44/p42 mitogen-activated protein kinase and extracellular acidification. Biochem Biophys Res Commun 1999;263:239-243.

36 Yacubova E, Komuro H. Stage-specific control of neuronal migration by somatostatin. Nature 2002;415: 77-81.

37 Hall A. Rho GTPases and the actin cytoskeleton. Science 1998;279:509-514.

38 Patel YC. Somatostatin and its receptor family. Front Neuroendocrinol 1999;20:157-198.

39 Petersen BE, Grossbard B, Hatch $\mathrm{H}$, et al. Mouse A6-positive hepatic oval cells also express several hematopoietic stem cell markers. Hepatology 2003; 37:632-640.

40 Fiegel HC, Park JJ, Lioznov MV, et al. Characterization of cell types during rat liver development. Hepatology 2003;37:148-154. 
41 Liu D, Martino G, Thangaraju M, et al. Caspase-8mediated intracellular acidification precedes mitochondrial dysfunction in somatostatin-induced apoptosis. J Biol Chem 2000;275:9244-9250.

42 Sharma K, Patel YC, Srikant CB. Subtype-selective induction of wild-type p53 and apoptosis, but not cell cycle arrest, by human somatostatin receptor 3 . Mol Endocrinol 1996;10:1688-1696.

43 Alderton F, Fan TP, Humphrey PP. Somatostatin receptor-mediated arachidonic acid mobilization: evidence for partial agonism of synthetic peptides. Br J Pharmacol 2001;132:760-766.

44 Sellers LA, Feniuk W, Humphrey PP, et al. Activated $G$ protein-coupled receptor induces tyrosine phosphorylation of STAT3 and agonist-selective serine phosphorylation via sustained stimulation of mitogen-activated protein kinase. Resultant effects on cell proliferation. J Biol Chem 1999;274:1642316430.

45 Rocheville M, Lange DC, Kumar U, et al. Subtypes of the somatostatin receptor assemble as functional homoand heterodimers. J Biol Chem 2000;275:7862-7869.

46 Bonig H, Priestley GV, Nilsson LM, et al. PTX-sensitive signals in bone marrow homing of fetal and adult hematopoietic progenitor cells. Blood 2004;104: 2299-2306.

47 Papakonstanti EA, Stournaras C. Association of PI-3 kinase with PAK1 leads to actin phosphorylation and cytoskeletal reorganization. Mol Biol Cell 2002;13: 2946-2962.

48 Qian Y, Zhong X, Flynn DC, et al. ILK mediates actin filament rearrangements and cell migration and invasion through PI3K/Akt/Rac1 signaling. Oncogene 2005; 24:3154-3165. 